\title{
Suppression of PDGF-induced PI3 kinase activity by imatinib promotes adipogenesis and adiponectin secretion
}

\author{
Stephen Fitter ${ }^{1}$, Kate Vandyke ${ }^{1}$, Stan Gronthos ${ }^{2,3}$ and Andrew C W Zannettino ${ }^{1,3}$ \\ ${ }^{1}$ Myeloma Research Laboratory, Bone and Cancer Research Laboratories, Department of Haematology, Institute of Medical and Veterinary Science, \\ Centre for Cancer Biology, SA Pathology, GPO Box 14, Adelaide, South Australia 5000, Australia \\ ${ }^{2}$ Mesenchymal Stem Cell Group, Department of Haematology, SA Pathology, Adelaide, South Australia, Australia \\ ${ }^{3}$ Robinson Institute, Centre for Stem Cell Research, University of Adelaide, Adelaide, South Australia, Australia
}

(Correspondence should be addressed to A C W Zannettino at Myeloma Research Laboratory; Email: andrew.zannettino@health.sa.gov.au)

\begin{abstract}
Improved glucose and lipid metabolism is a unique side effect of imatinib therapy in some chronic myeloid leukaemia (CML) patients. We recently reported that plasma levels of adiponectin, an important regulator of insulin sensitivity, are elevated following imatinib therapy in CML patients, which could account for these improved metabolic outcomes. Adiponectin is secreted exclusively from adipocytes, suggesting that imatinib modulates adiponectin levels directly, by transcriptional upregulation of adiponectin in pre-existing adipocytes, and/or indirectly, by stimulating adipogenesis. In this report, we have demonstrated that imatinib promotes adipogenic differentiation of human mesenchymal stromal cells (MSCs), which in turn secrete high-molecular-weight adiponectin. Conversely, imatinib does not stimulate adiponectin secretion from mature adipocytes. We hypothesise that inhibition of PDGFR $\alpha$ (PDGFRA) and PDGFR $\beta$ (PDGFRB) is the mechanism by which imatinib promotes adipogenesis. Supporting this, functional blocking antibodies to PDGFR promote adipogenesis and adiponectin secretion in MSC cultures. We have shown that imatinib is a potent inhibitor of PDGF-induced PI3 kinase activation and, using a PI3 kinase p110 $\alpha$-specific inhibitor (PIK-75), we have demonstrated that suppression of this pathway recapitulates the effects of imatinib on MSC differentiation. Furthermore, using mitogens that activate the PI3 kinase pathway, or MSCs expressing constitutively activated Akt, we have shown that activation of the PI3 kinase pathway negates the pro-adipogenic effects of imatinib. Taken together, our results suggest that imatinib increases plasma adiponectin levels by promoting adipogenesis through the suppression of PI3 kinase signalling downstream of PDGFR.
\end{abstract}

Journal of Molecular Endocrinology (2012) 48, 229-240

\section{Introduction}

Imatinib mesylate is a rationally designed chemotherapeutic agent that was developed to target the kinase domain of the BCR-ABL fusion protein, the causative molecular abnormality of chronic myeloid leukaemia (CML). Imatinib binds to the inactive ATPbinding pocket of BCR-ABL, preventing ATP binding and, subsequently, catalytic activity (Druker 2004). Imatinib has also been shown to inhibit the function of a number of off-target kinases, resulting in a range of unique side effects that are observed in some imatinibtreated patients (Vandyke et al. 2010b). For example, hyperphosphataemia and secondary hyperparathyroidism, observed in over $50 \%$ of imatinib-treated CML patients, are thought to relate to changes in normal bone remodelling resulting from inhibition of the macrophage colony-stimulating factor (CSF1) receptor, c-fms (CSF1R) and the platelet-derived growth factor receptor (PDGFR). At therapeutically achievable concentrations, imatinib inhibits c-fms, thereby suppressing osteoclast differentiation and function (Dewar et al. 2005, 2006). Conversely, imatinib is thought to stimulate osteogenesis by inhibiting PDGFR signalling in pluripotent mesenchymal stromal cells (MSCs; Fierro et al. 2007, Fitter et al. 2008, Jonsson et al. 2011). Assessment of skeletal elements in CML patients, before and after imatinib treatment, has revealed an increase in trabecular bone volume and increased bone mineral density consistent with an antiosteoclastic and/or pro-osteogenic effect (Fitter et al. 2008, Jonsson et al. 2008, O’Sullivan et al. 2009).

Improved glucose metabolism has also emerged as an off-target effect of imatinib therapy in some CML patients. This side effect appears to be limited to CML patients with concurrent type 2 diabetes or those who are insulin resistant (Tsapas et al. 2008), as no improvement in fasting glucose levels was observed in non-diabetic CML patients with normoglycaemic profiles at diagnosis (Mariani et al. 2010). Typically, responsive patients experience a significant increase in insulin sensitivity within 3 months of commencing imatinib therapy (Breccia et al. 2004, 2005, Veneri et al. 2005, Gologan et al. 2009, Mariani et al. 2010). This improvement occurs without significant dietary or 
lifestyle changes, suggesting that imatinib modulates systemic insulin sensitivity. In support of this, improved glycaemic control has also been observed following imatinib treatment in animal models of diabetes. In streptozotocin-induced and spontaneous (non-obese diabetic and $d b / d b)$ mouse models of diabetes, imatinib has been shown to preserve islet $\beta$-cell function, in part through the suppression of c-abl-mediated islet cell apoptosis (Hagerkvist et al. 2007, Han et al. 2009). Imatinib and other inhibitors of PDGFR have also been shown to prevent and even reverse diabetes in nonobese diabetic mice through a mechanism that may involve suppression of a PDGF-induced inflammatory response (Louvet et al. 2008). More recently, we have demonstrated that plasma levels of an adipokine, adiponectin, are elevated two- to three-fold in CML patients after 3 months of imatinib therapy (Fitter $e t$ al. 2010). Adiponectin is known to play an important role in glucose metabolism, suggesting that this increase in adiponectin may be a mechanism whereby imatinib causes improvements in insulin sensitivity. In support of this, the increase in plasma adiponectin levels observed following imatinib treatment occurs within a similar time frame as the improvements in insulin sensitivity observed in imatinib-treated CML patients (Breccia et al. 2004, 2005, Veneri et al. 2005, Gologan et al. 2009, Mariani et al. 2010).

Adiponectin is secreted exclusively from peripheral, omental and bone marrow adipose, where its expression is regulated in response to metabolic effectors. Intramedullary adipose is derived from pluripotent MSCs that reside within the bone marrow microenvironment. Differentiation occurs in response to a variety of extrinsic factors that act to initiate or repress the transcriptional programs that govern lineage determination (Gimble 1998). Examination of the bone marrow cellularity of CML patients before and after imatinib therapy revealed a significant increase in intramedullary adipose after 6 months of therapy (Fitter et al. 2010). Furthermore, we and others have observed increased adipocyte numbers in MSC cultures treated with therapeutically relevant doses of imatinib (Fierro et al. 2007, Fitter et al. 2008). Taken together, these findings suggest that imatinib promotes adipogenic differentiation of human MSCs.

In this study, we have shown that imatinib promotes adipogenic differentiation and adiponectin secretion from human MSCs and have identified the PI3 kinase pathway, downstream of PDGFR, as an important mechanism.

\section{Materials and methods}

\section{Reagents}

Imatinib mesylate and NVP-BEZ235 were provided by Novartis International. PI3 kinase isoform-specific inhibitors PIK-75 (p110 $\alpha)$, TGX-221 (p110 $\beta$ ) and
IC87114 (p110ס) were a kind gift from Prof. Peter Shepherd (Maurice Wilkins Centre for Molecular Biodiscovery, University of Auckland, New Zealand). Pioglitazone was purchased from Cayman (Ann Arbor, MI, USA). Stock solutions of inhibitors were prepared in $100 \%$ DMSO and subsequent dilutions made in media. Unless otherwise specified, all reagents were purchased from Sigma.

\section{MSC isolation and differentiation}

MSCs were grown from bone chips recovered from posterior iliac crest bone marrow aspirates from haematologically normal human donors as described previously (Fitter et al. 2008) and in accordance with procedures approved by the Royal Adelaide Hospital Ethics Committee. To stimulate adipogenesis, cells were cultured in media with reduced foetal bovine serum $(5 \% \mathrm{v} / \mathrm{v})$ and supplemented with $100 \mathrm{nmol} / 1$ dexamethasone sodium phosphate (induction media) for 35 days. Conditioned media were collected from control and imatinib-treated cultures 4 days post-media change and stored at $-80^{\circ} \mathrm{C}$. To identify and enumerate lipid-laden fat cells, formalinfixed cells in 96-well plates were stained with nile red $(25 \mathrm{ng} / \mathrm{ml})$ and DAPI $(300 \mathrm{nmol} / \mathrm{l})$ for $15 \mathrm{~min}$. Nile red-labelled adipocytes and DAPI-stained cell nuclei were visualised using an inverted fluorescence microscope (CKX41; Olympus, Tokyo, Japan), images were captured using a colour CCD camera $(4 \times$ magnification; DP20, Olympus) and adipocytes and cell nuclei were enumerated using Image $\mathrm{J}$ software. For mitogen experiments, induction cultures were treated with rhPDGF-BB (10 ng/ml; Prospec, Rehovot, Israel) or rhEGF (20 ng/ml; Prospec) twice weekly for 4 weeks and adipocytes were enumerated as described.

\section{Real-time PCR}

Total RNA was isolated using Trizol (Invitrogen) and real-time PCR was performed as described previously (Fitter et al. 2008). Changes in gene expression were calculated relative to $\beta$-actin using the $2^{-\Delta C_{\mathrm{t}}}$ method. Primer pairs (forward and reverse) were as follows: $\beta$-actin $(A C T B), 5^{\prime}$-gatcattgctcctcctgagc- $3^{\prime}$ and $5^{\prime}$-gtcatagtccgcctagaagcat-3'; CCAAT/enhancer binding protein, alpha (CEBPA), 5'-gggcaaggccaagaagtc- $3^{\prime}$ and $5^{\prime}$-ttgtcactggtcagctccag- $3^{\prime}$; peroxisome proliferator-activated receptor gamma 2 (PPARG), $5^{\prime}$-ctcctattgacccagaaagc- $3^{\prime}$ and $5^{\prime}$-tcaaaggagtgggagtggtc-3'; leptin $(L E P), \quad 5^{\prime}$-ggctttggccctatcttttc-3' and $5^{\prime}$-accggtgactttctgtttgg- $3^{\prime}$; complement factor $\mathrm{D}(C F D), 5^{\prime}$-gacaccatcgaccacgac- $3^{\prime}$ and $5^{\prime}$-ccacgtcgcagagagttc-3'; retinoic acid receptor responder (tazarotene induced) 2 (RARRES2), 5'-aagcatgcgacggctgctga-3' and $5^{\prime}$-agctgggaagggcgtgtcca-3'; and adiponectin (ADIPOQ), $5^{\prime}$-gctgggagctgttctactgc- $3{ }^{\prime}$ and $5^{\prime}$-cgatgtctccettaggacca- $3^{\prime}$. 


\section{Immunoblotting}

Analysis of adiponectin multimers was performed as described previously (Lara-Castro et al. 2006, Fitter et al. 2010). Briefly, conditioned media were electrophoresed on $8-13 \%$ non-denaturing sodium acetate PAGEs (Invitrogen) and protein complexes transferred to PVDF membrane, blocked for $2 \mathrm{~h}$ in $2.5 \%(\mathrm{w} / \mathrm{v})$ blocking buffer (GE Healthcare, Little Chalfont, UK) and probed for $16 \mathrm{~h}$ at $4{ }^{\circ} \mathrm{C}$ using an adiponectinspecific antibody (BD Biosciences, Franklin Lakes, NJ, USA). Bound antibody was detected using an alkaline phosphatase-conjugated secondary antibody and then visualised on a Typhoon 9410 imager (GE Healthcare) in the presence of an enhanced chemifluorescence substrate. To assess total adiponectin levels, an equivalent amount of culture medium was resolved by denaturing SDS-PAGE $(10 \% \mathrm{v} / \mathrm{v})$, transferred to PVDF membranes and immunoblotted as described earlier. To measure cellular proteins, cell lysates were obtained as described previously (Fitter et al. 2008) and equivalent amounts $(50 \mu \mathrm{g})$ of protein separated on $10 \%$ SDS-PAGE gels and transferred to PVDF membranes. Target proteins were detected using antigenspecific antibodies $(\mathrm{C} / \mathrm{EBP} \alpha$ and PPAR $\gamma 2$, Millipore, Billerica, MA, USA; $\beta$-actin, Sigma; HSP-90, Santa Cruz Biotechnology, Santa Cruz, CA, USA).

PDGF pulse experiments were carried out as described previously (Fitter et al. 2008). Briefly, MSCs were grown to 80-90\% confluence in $6 \mathrm{~cm}$ dishes and serum deprived for $16 \mathrm{~h}$. Cells were exposed to drugs (at indicated concentrations) for $1 \mathrm{~h}$ and then pulse stimulated with rhPDGF-BB $(10 \mathrm{ng} / \mathrm{ml})$ for $5 \mathrm{~min}$. Equivalent amounts of protein $(50 \mu \mathrm{g})$ were separated on $10 \%$ SDS-PAGE gels and transferred to PVDF membranes. Target proteins were detected using antigen-specific antibodies (phospho-Akt [Thr 308] and phospho-Erk1/2 [Thr 202/Tyr 204]; Cell Signaling, Danvers, MA, USA) as described earlier. Data are representative of results from three MSC donors.

\section{ELISA}

Adiponectin levels in cell culture conditioned media were measured using a commercial ELISA kit (R\&D Systems, Minneapolis, MA, USA). Frozen conditioned media were thawed at $4{ }^{\circ} \mathrm{C}$, centrifuged at $16000 \mathrm{~g}$ for $15 \mathrm{~min}$ at $4{ }^{\circ} \mathrm{C}$ and adiponectin levels were determined in triplicate according to the manufacturer's instructions. The inter-plate coefficient of variation was calculated as $2 \cdot 5-7 \cdot 5(\%)$.

\section{Cell proliferation assay}

The effect of functional blocking antibodies to PDGFR $\alpha$ (PDGFRA) and PDGFR $\beta$ (PDGFRB; $10 \mu \mathrm{g} / \mathrm{ml}$; Millipore), control $\operatorname{IgG}(10 \mu \mathrm{g} / \mathrm{ml})$ and imatinib $(3 \mu \mathrm{mol} / \mathrm{l})$ on cell survival/proliferation was assessed using WST-1 as described previously (Vandyke $e t a l .2010 a$ ) .

\section{Generation of MSCs expressing myristoylated Akt}

A cDNA encoding a $5^{\prime}$-src myristoylation signal in frame with mouse Akt1 (myr-Akt; a gift from Dr Naheed N Ahmed, Fox Chase Cancer Center, Philadelphia, PA, USA) was sub-cloned into pRUF-IRES-eGFP and then introduced into primary human MSCs by retroviral transduction as described previously (Isenmann et al. 2009). Infected cells $\left(\mathrm{eGFP}^{+}\right)$were isolated by preparative flow cytometry and used in differentiation assays. Constitutive Akt activity was confirmed by immunoblotting using a phospho-specific p70S6K antibody (Cell Signaling) and a total p70S6K antibody (Cell Signaling).

\section{Statistical analysis}

Statistical analysis was performed using GraphPad Prism (Version 5; GraphPad Software, La Jolla, CA, USA). $t$-Tests or one-way ANOVA with Dunnett's post-tests were applied where indicated. Two-sided $P$ values $<0 \cdot 05$ were considered statistically significant.

\section{Results}

\section{Imatinib stimulates adipogenesis}

Differentiation of human MSCs into adipocytes in vitro is typically performed using a drug cocktail containing PPAR $\gamma 2$ agonists, phosphodiesterase inhibitors and glucocorticoid, the latter being essential to drive differentiation (Gimble 1998). To examine the effect of imatinib, we chose to use only glucocorticoid (100 nmol/1 dexamethasone) to more closely emulate physiological conditions.

At therapeutically relevant doses of imatinib (le Coutre et al. 2004), a dose-dependent increase in adipocyte numbers was observed (Fig. 1A and B). Realtime PCR was utilised to investigate transcriptional changes in genes involved in adipogenic differentiation and function. In response to imatinib, the expression of key adipogenic transcription factors $C E B P A$ and PPARG was elevated at all time points examined (Fig. 1C). Imatinib treatment also stimulated the expression of several adipokines including $L E P, C F D$ and RARRES2. Most profoundly, adiponectin gene expression $(A D I P O Q)$ was elevated up to 70 -fold in imatinib-treated cultures at day 32, when compared with the vehicle control (Fig. 1B). Consistent with the transcriptional increases seen in response to imatinib, an increase in $\mathrm{C} / \mathrm{EBP} \alpha, \operatorname{PPAR} \gamma 2$ and adiponectin protein levels were detected by immunoblotting (Fig. 1D). 
A
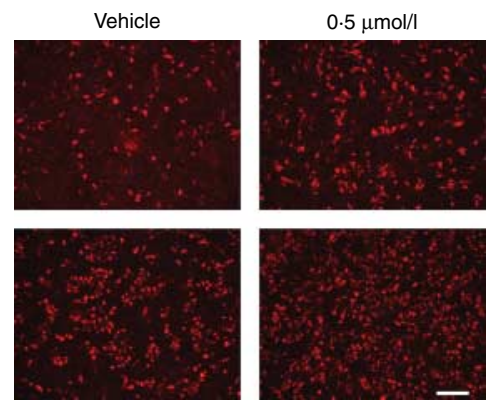

B

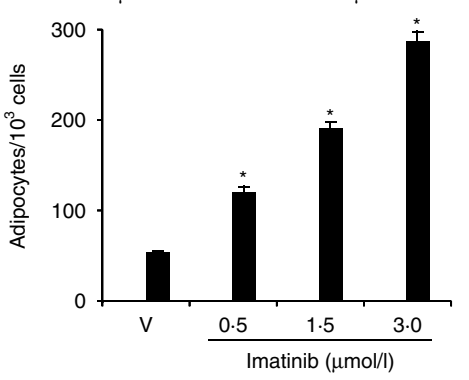

C
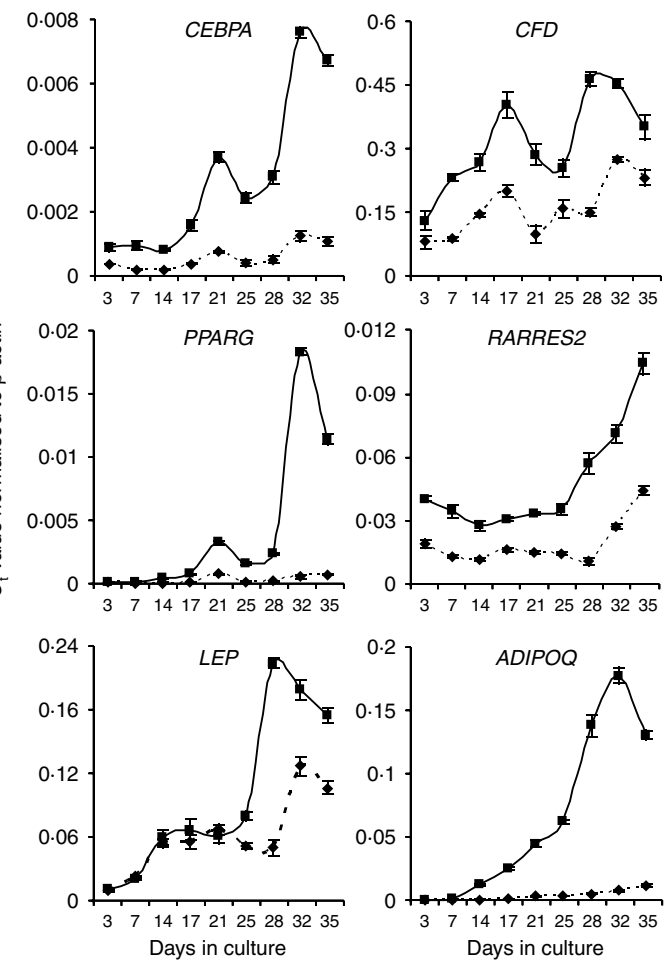

D

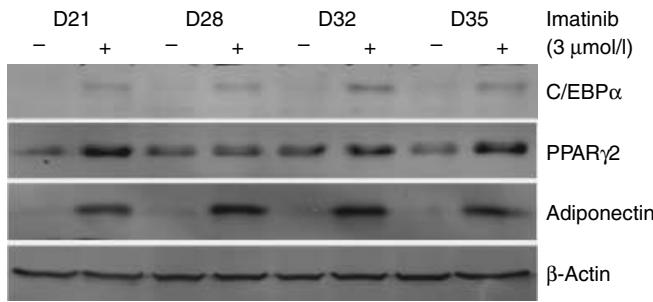

Adipocytes in imatinib-treated cultures secrete high-molecular-weight adiponectin

To investigate whether adiponectin was secreted from imatinib-treated MSCs, an adiponectin-specific ELISA was used. Consistent with the gene expression studies, increased levels of secreted adiponectin were detectable in the conditioned media of MSCs cultured in the presence of imatinib for 21 days or longer (Fig. 2A).

To determine the nature of adiponectin complexes secreted from adipocytes in imatinib-treated MSC cultures, conditioned media were analysed by nondenaturing PAGE and western blotting. The predominant secreted form is the high-molecular-weight (HMW) complex that was evident from 17 to 21 days of culture (Fig. 2B).

To determine whether imatinib promotes adiponectin secretion from mature adipocyctes, MSCs were cultured under induction conditions in the presence of imatinib for 28 days to promote adipogenesis. The induction medium was then replaced with normal growth medium for 4 days after which time differentiated adipocyte cultures were stimulated with imatinib or the known PPAR $\gamma 2$ agonists pioglitazone or indomethacin for 4 days in induction media. Conditioned media were collected and adiponectin levels were determined by ELISA. No significant increase in adiponectin secretion was observed in differentiated cultures treated with imatinib, whereas both pioglitazone and indomethacin strongly promoted adiponectin secretion when compared with the vehicle control (Fig. 2C).

\section{Blocking antibodies to PDGFR promote adipogenesis and adiponectin secretion}

Imatinib inhibits a number of non-receptor and receptor tyrosine kinases. These include PDGFR, which is highly expressed on mesenchymal cells. PDGF acts as a potent MSC mitogen and an inhibitor of osteogenic and adipogenic differentiation (Kratchmarova et al. 2005, Tokunaga et al. 2008). In light of this,

Figure 1 Imatinib stimulates adipogenesis. (A) Primary human MSCs were treated with imatinib (as indicated) or vehicle (PBS) in induction media for 35 days and adipocytes visualised using nile red. (B) The number of adipocytes was enumerated by counting nile red-labelled cells and DAPI-labelled cell nuclei (mean \pm s.D. of triplicate measurements; ${ }^{*} P<0.001$. One-way ANOVA with Dunnett's post-test). (C) Temporal gene expression analysis of adipocyte-specific genes in imatinib-treated ( $3 \mu \mathrm{mol} / \mathrm{l})$ (solid lines) and vehicle-treated (dashed lines) primary human MSC cultures. RNA was harvested at the indicated time points, reverse transcribed into cDNA and comparative gene expression studies performed using real-time PCR. Line graphs show temporal changes in gene expression for indicated genes (mean \pm s.D. of triplicate measurements). (D) Protein lysates from imatinibtreated $(+)$ and vehicle-treated $(-)$ cultures were isolated at the indicated time points and subjected to immunoblotting using antigen-specific antibodies as indicated. Bar $=500 \mu \mathrm{m}$. 


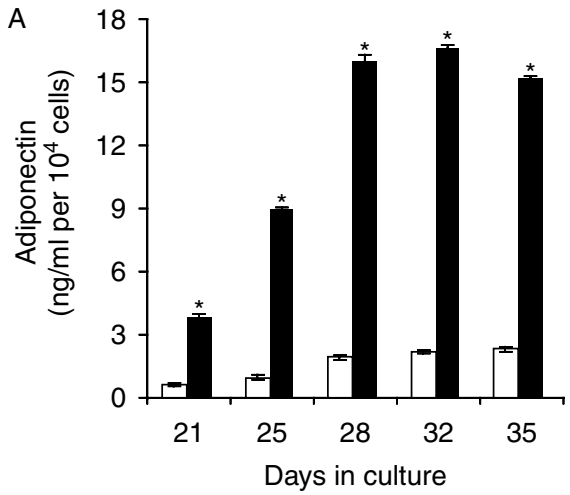

B
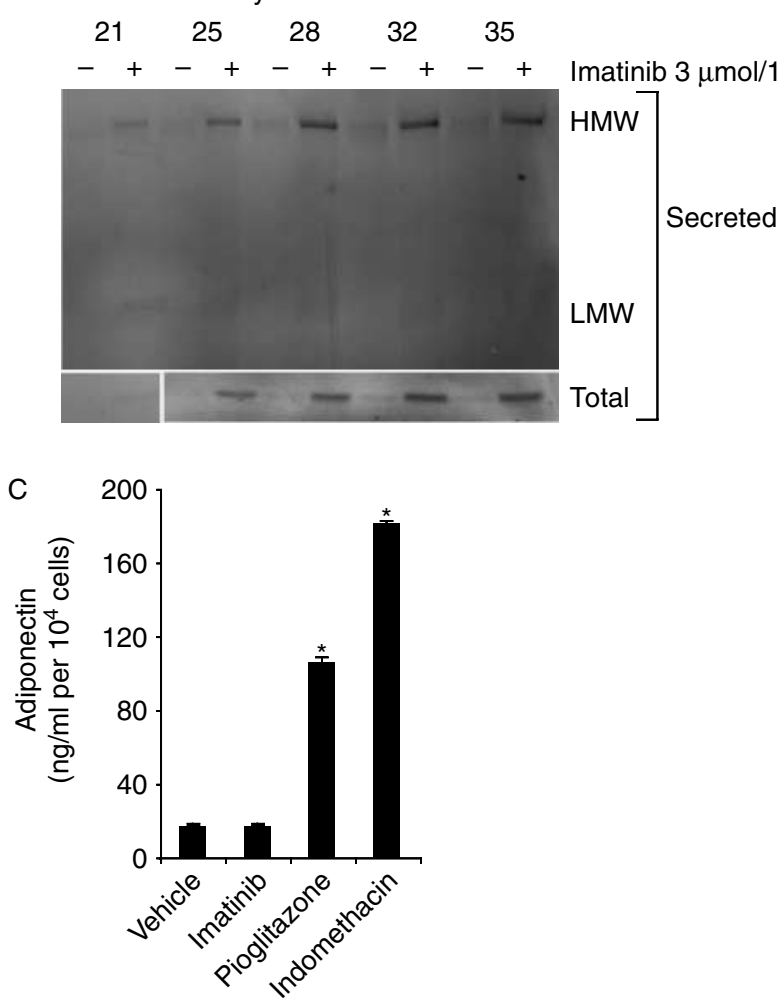

Figure 2 Adipocytes formed in imatinib-treated cultures secrete adiponectin. (A) MSCs were cultured under induction conditions in the presence of vehicle (PBS, white bars) or imatinib $(3 \mu \mathrm{mol} / \mathrm{l}$, black bars). Conditioned media were collected from cultures, at the indicated time intervals, and secreted adiponectin levels measured by ELISA (mean \pm S.D. of triplicate measurements; ${ }^{\star} P<0.005$, $t$-test, relative to PBS control). (B) Secreted adiponectin was analysed by non-denaturing PAGE, to identify complexes, and denaturing PAGE, to detect total adiponectin, followed by immunoblotting. Molecular weights: HMW, $\sim 360 \mathrm{kDa}$; LMW, 180 kDa; total, $30 \mathrm{kDa}$. (C) MSC cultures were treated with $3 \mu \mathrm{mol} / \mathrm{l}$ imatinib for 28 days, then stimulated with vehicle ( $0.1 \% \mathrm{DMSO})$, imatinib $(3 \mu \mathrm{mol} / \mathrm{l})$, pioglitazone $(2 \mu \mathrm{mol} / \mathrm{l})$ or indomethacin $(60 \mu \mathrm{mol} / \mathrm{l})$ and secreted adiponectin measured by ELISA (mean \pm S.D. of triplicate measurements; ${ }^{\star} P<0.001$. One-way ANOVA with Dunnett's post-test). we hypothesised that imatinib mediates its effects through inhibition of PDGFR function. To test this, functional blocking antibodies to PDGFR $\alpha$ and PDGFR $\beta$ were included in MSC cultures under induction conditions. An antibody concentration $(10 \mu \mathrm{g} / \mathrm{ml})$ that inhibited cell proliferation and PDGF-induced activation of Akt equivalent to that observed following treatment with $3 \mu \mathrm{M}$ imatinib was selected (Fig. 3A and B). Consistent with a role for PDGF as an inhibitor of differentiation, blocking antibodies to PDGFR promoted the formation of adipocytes in MSC cultures (Fig. 3C and D), and this was associated with an up-regulation of PPAR $\gamma 2$ and adiponectin gene expression (Fig. 3E). Adipocytes formed in the presence of functional blocking antibodies to PDGFR $\alpha$ and PDGFR $\beta$ were shown to secrete the HMW form of adiponectin, consistent with the effects of imatinib (Fig. 3F and G).

\section{Inhibition of $\mathrm{p} 110 \alpha$ promotes adipogenesis and adiponectin secretion}

In mesenchymal cells, stimulation with PDGF has been shown to strongly activate the PI3 kinase pathway, as evidenced by the phosphorylation of the regulatory and catalytic subunits of class I PI3 kinase family members and downstream effector molecules such as Akt (Kratchmarova et al. 2005). Suppression of PI3 kinase using pharmacological inhibitors has been shown to promote MSC differentiation (Kratchmarova et al. 2005, Fitter et al. 2008, Martin et al. 2010), suggesting that this pathway is important for transducing the inhibitory effects of PDGF on MSC differentiation. Consistent with this hypothesis, imatinib is a potent inhibitor of PDGF-induced PI3 kinase activation, as evidenced by a dose-dependent decrease in the phosphorylation of Akt (Fig. 4A). By contrast, PDGFinduced Erk activation, a measure of MAPK activity, is not affected by imatinib treatment (Fig. 4A).

In light of the inhibitory effect of imatinib on PDGFinduced PI3 kinase activation, we hypothesised that an inhibitor of the catalytic subunit of PI3 kinase would promote adipogenesis. As MSCs express PI3 kinase subunits $\mathrm{p} 110 \alpha, \mathrm{p} 110 \beta$ and $\mathrm{p} 110 \delta$ (data not shown), the isoform-specific inhibitors BEZ235, PIK-75, TGX-221 and IC87114 were tested initially to assess the role of each subunit in PDGF-induced Akt activation. Only PIK-75, an inhibitor of $p 110 \alpha$ (Chaussade et al. 2007) and BEZ235, a pan class I inhibitor (Serra et al. 2008), were found to inhibit PDGF-induced Akt phosphorylation (Fig. 4B). PIK-75 inhibits PDGF-induced Akt phosphorylation dose dependently (Fig. 4C) with an $\mathrm{IC}_{50}$ of $10 \mathrm{nM}$.

Consistent with the results obtained for imatinib and functional blocking PDGFR antibodies, PIK-75 was shown to dose dependently promote adipocyte formation under induction conditions (Fig. 4D and E). Similarly, high levels of secreted HMW and LMW 
adiponectin complexes were detected in cultures treated with PIK-75 for 18 days or more, when compared with vehicle-treated control cultures (Fig. 4F and G).

\section{Mitogens that activate PI3 kinase negate the proadipogenic effects of imatinib but not PIK-75}

To further investigate the role of the PI3 kinase pathway in MSC differentiation, we examined the effects of adding

A Anti-PDGFR $(\mu \mathrm{g} / \mathrm{ml})$
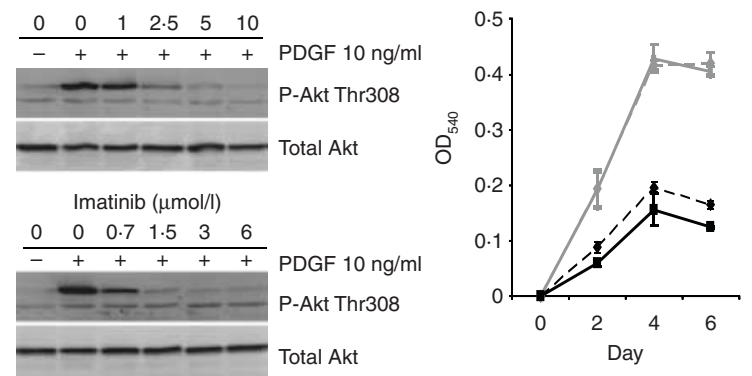

C

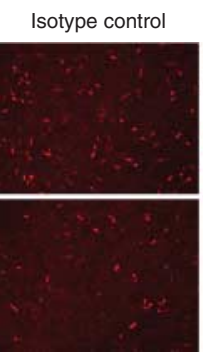

Vehicle
PDGFR $\alpha / \beta$ blocking

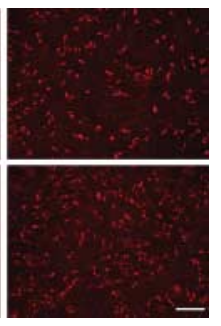

Imatinib $(3 \mu \mathrm{mol} / \mathrm{l})$

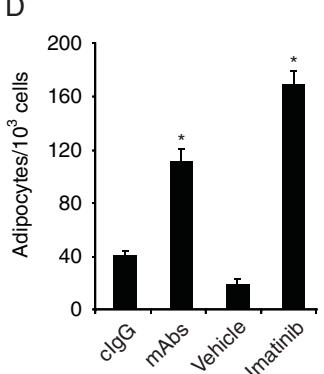

E

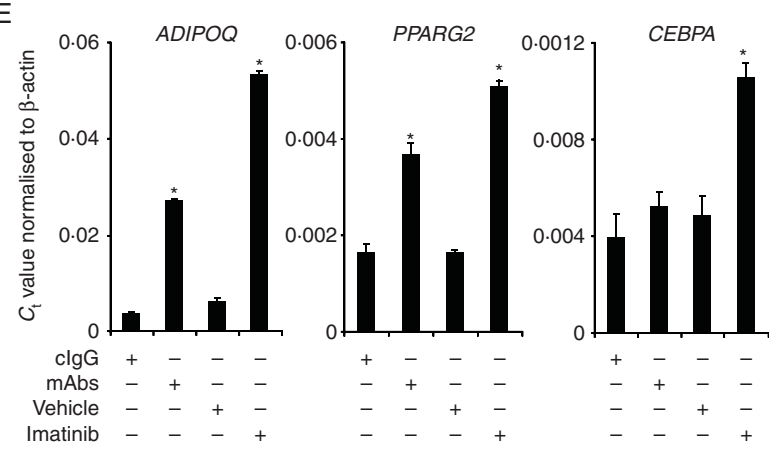

$\mathrm{F}$

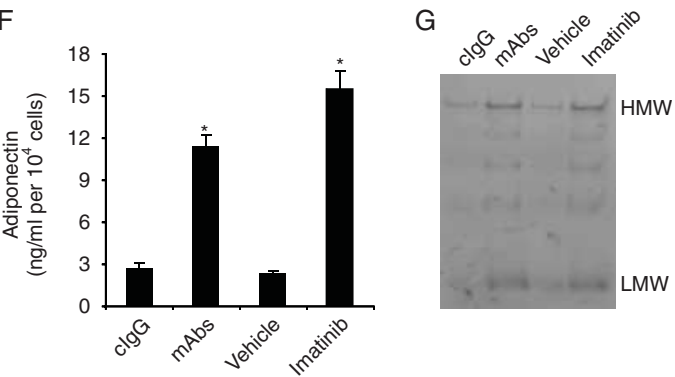

exogenous mitogens to imatinib or PIK-75-treated MSC cultures under induction conditions. Both PDGF and EGF activate the PI3 kinase pathway in human MSCs (Kratchmarova et al. 2005). Consistent with previous reports (Artemenko et al. 2005, Gagnon et al. 2009), we found that addition of growth factors alone completely inhibited glucocorticoid-induced adipogenesis (Fig. 5A and B). In the presence of imatinib, PDGF had no effect on imatinibmediated adipogenesis whereas EGF inhibited the imatinib response (Fig. 5A and B). In contrast, PIK-75 promoted adipogenesis, albeit to a lesser extent, in the presence of either PDGF or EGF (Fig. 5A and B), suggesting that the PI3 kinase pathway is important for transducing the inhibitory effects of mitogens on MSC differentiation.

\section{Constitutive activation of Akt negates the effects of imatinib on MSC differentiation}

Having established a signalling pathway that links imatinib with MSC differentiation, we sought to confirm our findings using a genetic approach. Akt is the primary effector molecule of the PI3 kinase pathway, and its activation is suppressed by imatinib in response to PDGF stimulation. It therefore follows that constitutive activation of Akt would negate the pro-adipogenic effects of imatinib. To test this, MSC cultures that express constitutively activated Akt (myr-Akt) or vector only were treated with imatinib and their ability to differentiate into adipocytes was measured. To confirm activation of Akt, the phosphorylation status of p70S6K, an Akt effector

Figure 3 Functional blocking antibodies to PDGFR promote adipogenesis. (A) MSC cultures were starved overnight, treated with functional blocking anti-PDGFR antibodies or imatinib and then stimulated with rhPDGF-BB $(10 \mathrm{ng} / \mathrm{ml})$ for $5 \mathrm{~min}$. Cell proteins were harvested, resolved by SDS-PAGE and then transferred to PVDF membranes. The activation status of Akt was determined using a phospho-specific antibody. (B) MSCs were cultured in normal growth medium supplemented with functional blocking PDGFR $\alpha$ and PDGFR $\beta$ antibodies (mAbs, $10 \mu \mathrm{g} / \mathrm{ml}$, black dashed line), isotype control antibodies (clgG, $10 \mu \mathrm{g} / \mathrm{ml}$, grey dashed line), imatinib ( $3 \mu \mathrm{mol} / /$, black solid line) or vehicle (PBS, grey solid line) for 6 days. The relative number of viable, metabolically active cells per well was then detected using WST-1 reagent read at $540 \mathrm{~nm}$. (C) MSC cultures were treated with $\mathrm{mAbs}, \mathrm{clgG}$, imatinib $(3 \mu \mathrm{mol} / \mathrm{l})$ or vehicle (PBS) under induction conditions for 28 days and adipocytes were visualised using nile red. (D) The number of adipocytes was enumerated by counting nile red-labelled cells and DAPI-labelled cell nuclei (mean \pm S.D. of triplicate measurements). (E) RNA harvested from treated cultures was reverse transcribed into cDNA and comparative gene expression studies performed using real-time PCR. Bar graphs show changes in gene expression for indicated genes (mean \pm s.D. of triplicate measurements). (F) An ELISA was used to determine the amount of adiponectin secreted from MSC cultures treated as indicated. (G) Secreted adiponectin was analysed by non-denaturing PAGE and immunoblotting. Molecular weights: HMW, $\sim 360 \mathrm{kDa}$; LMW, $\sim 180 \mathrm{kDa}\left({ }^{\star} P<0 \cdot 05\right.$. $t$-test, relative to controls). Bar $=500 \mu \mathrm{m}$. 
molecule (Hay \& Sonenberg 2004), was assessed. Hyperphosphorylated p70S6K was detected in immunoblots of proteins isolated from cells expressing myr-Akt, when compared with vector-only control cells lysates (Fig. 6A). Under induction conditions, imatinib promoted adipogenic differentiation of vector control cells but failed to promote adipogenesis in hMSCs expressing myr-Akt (Fig. 6B). By contrast, indomethacin, a PPAR agonist (Lehmann et al. 1997), promoted adipogenesis in both control and myr-Akt-expressing cells.
A
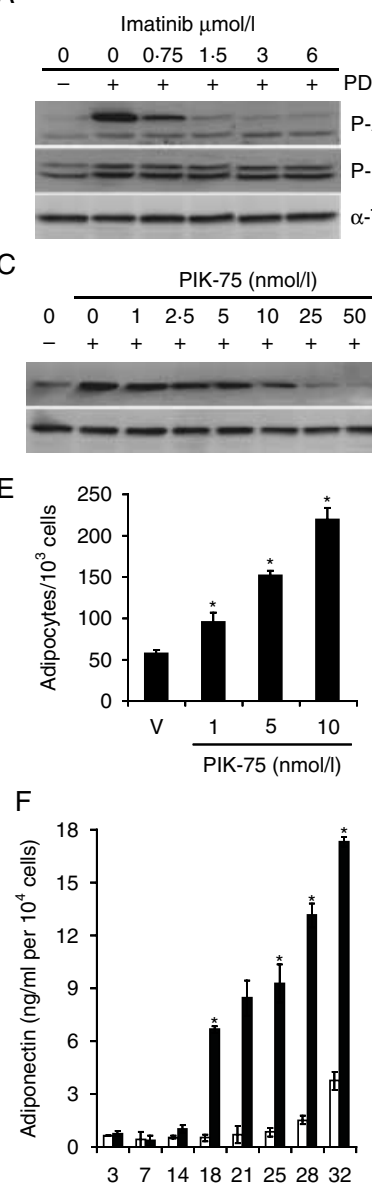

Days in culture
B

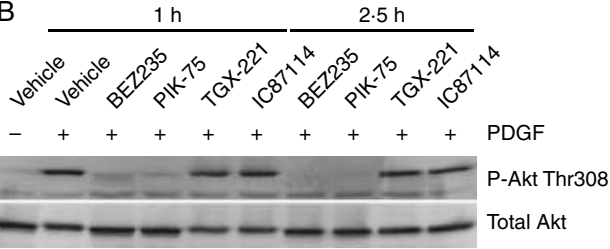

D
$1 \mathrm{nmol} / \mathrm{l}$
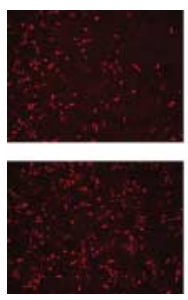

$5 \mathrm{nmol} / \mathrm{l}$
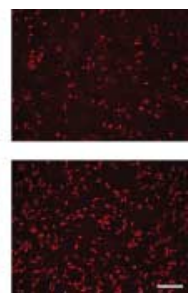

$10 \mathrm{nmol} / \mathrm{l}$

Total Akt

G $\begin{array}{lllllllll}\text { D3 } & \text { D7 } & \text { D14 } & \text { D18 } & \text { D21 } & \text { D25 } & \text { D28 } & \text { D32 } & \text { PIK-75 }\end{array}$ $-+-+-+-+-+-+++-+(10 \mathrm{nmol} / \mathrm{l})$

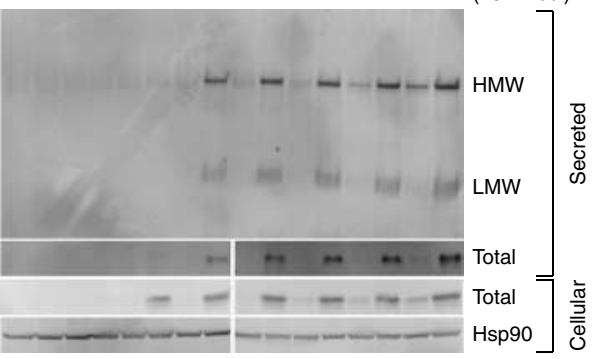

Figure 4 Suppression of $\mathrm{p} 110 \alpha$ promotes adipogenesis. (A) MSC cultures were starved overnight, treated with imatinib or vehicle (PBS), as indicated, and then stimulated with rhPDGFBB $(10 \mathrm{ng} / \mathrm{ml})$ for $5 \mathrm{~min}$. Cell proteins were harvested, resolved by SDS-PAGE and then transferred to PVDF membranes. The activation status of PDGFR effector molecules was determined using phospho-specific antibodies as indicated. (B) Starved MSC cultures were treated with vehicle (0.1\% DMSO), NVP-BEZ235 (100 nmol/l), PIK-75 (50 nmol/l), TGX-221 $(200 \mathrm{nmol} / \mathrm{l})$ or IC87114 $(2 \mu \mathrm{mol} / \mathrm{l})$ for the indicated times, pulsed with rhPDGF-BB and the phosphorylation status of Akt was determined by immunoblotting. (C) Starved MSC cultures were treated with PIK-75 (as indicated) or vehicle (0.1\% DMSO) for $1 \mathrm{~h}$, pulsed with rhPDGF-BB and the phosphorylation status of Akt was determined by immunoblotting. (D) MSC cultures were treated with PIK-75 (as indicated) or vehicle (0.1\% DMSO) under induction conditions for 32 days and adipocytes visualised using nile red. (E) The number of adipocytes was enumerated by counting nile red-labelled cells and DAPI-labelled cell nuclei (mean \pm s.D. of triplicate measurements; ${ }^{*} P<0 \cdot 001$. One-way ANOVA with Dunnett's post test. (F) An ELISA was used to determine the amount of adiponectin secreted from PIK-75 (10 nmol/l)-treated MSC cultures (black bars) and vehicle controls (white bars) at the indicated time points (mean \pm S.D. of triplicate measurements). (G) Secreted adiponectin was analysed by non-denaturing PAGE, to identify complexes, and denaturing PAGE, to detect total adiponectin, followed by immunoblotting. Cellular adiponectin was analysed by denaturing PAGE and immunoblotting. As a loading control, heat-shock protein 90 (HSP90) levels are shown. Molecular weights: HMW, $\sim 360 \mathrm{kDa}$; LMW, $\sim 180 \mathrm{kDa}$; total, $30 \mathrm{kDa}$. ( ${ }^{*} P<0.005$. $t$-test, relative to controls). Bar $=500 \mu \mathrm{m}$. 
A
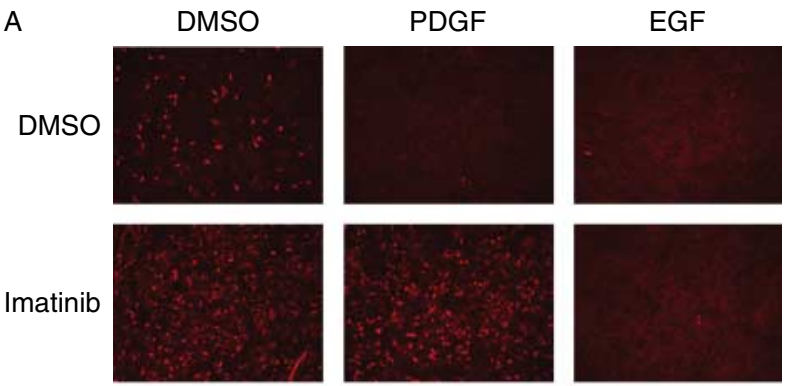

PIK-75
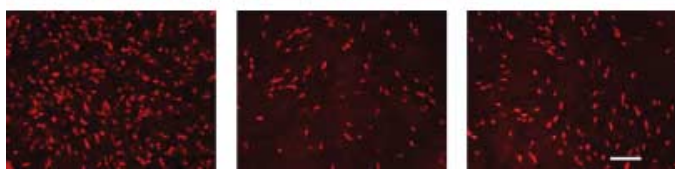

B

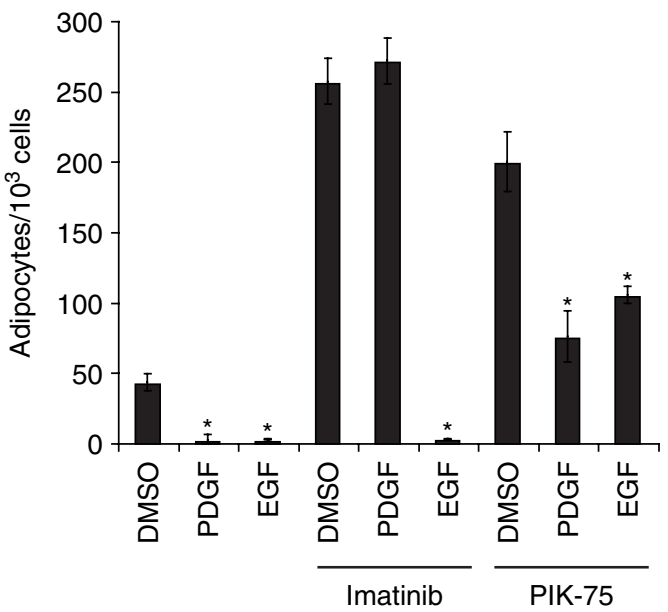

Figure 5 Mitogens that activate PI3 kinase negate the proadipogenic effects of imatinib. MSC cultures were stimulated with rhPDGF-BB $(10 \mu \mathrm{g} / \mathrm{ml})$ or rhEGF $(20 \mathrm{ng} / \mathrm{ml})$ in the presence or absence of imatinib $(3 \mu \mathrm{mol} / \mathrm{l})$ or PIK-75 $(10 \mathrm{nmol} / \mathrm{l})$ for 28 days. (A) Adipocytes were labelled using nile red. (B) The number of adipocytes were enumerated by counting nile red-labelled cells and DAPI-labelled cell nuclei (mean \pm s.D. of triplicate measurements; ${ }^{\star} P<0 \cdot 001$. One-way ANOVA with Dunnett's post-test). $\mathrm{Bar}=500 \mu \mathrm{m}$

\section{Discussion}

Here, we demonstrate that therapeutically relevant concentrations of imatinib promote the differentiation of human MSCs into adipocytes, which in turn secrete the HMW form of adiponectin. Imatinib failed to promote adiponectin secretion from mature adipocytes, suggesting that imatinib does not promote adiponectin secretion through a direct effect on adiponectin gene expression but rather indirectly through an effect on adipocyte numbers.

MSCs are pluripotent and lineage specificity can be orchestrated in vitro using a combination of ligands that act directly, or indirectly, to drive lineage-specific transcription factors (Pittenger et al. 1999). Crucial to this response is the addition of glucocorticoid that acts to prime cells to be responsive to differentiation signals (Gimble 1998). Treatment of MSCs with imatinib alone is sufficient to stimulate adipogenesis in glucocorticoidtreated cells, as evidenced by a temporal increase in key adipogenic transcription factors $\mathrm{C} / \mathrm{EBP} \alpha$ and $\mathrm{PPAR} \gamma 2$, the accumulation of lipid-laden vacuoles and secretion of the adipokine adiponectin. Glucocorticoid-treated cells appear highly sensitive to the pro-adipogenic effects of imatinib, resulting in adipogenic differentiation of MSCs at hydrocortisone concentrations well below physiological levels ( $5 \mathrm{nmol} / \mathrm{l}$; data not shown). As the reductase required to regenerate active cortisone in vivo, 11ß-hydroxysteroid dehydrogenase type I (11ßHSD), is highly expressed in MSCs and bone cells (Justesen et al. 2004), bone marrow-synthesised steroid and imatinib could act locally on MSC populations to drive adipogenic differentiation.

Previous studies have demonstrated that PDGF is a potent MSC mitogen that has been shown to inhibit MSC differentiation (Hock \& Canalis 1994, Kubota et al. 2002, Chaudhary et al. 2004, Kratchmarova et al. 2005). Imatinib is a potent PDGFR inhibitor (Buchdunger et al. 2000), suggesting that imatinib mediates its proadipogenic effects through inhibition of PDGFR. In support of this, we have shown that functional blocking antibodies to PDGFR promote adipogenesis and adiponectin secretion when used at concentrations that suppress cell proliferation and PDGF-induced Akt activation similar to that achieved with imatinib. We therefore hypothesise that, in cultures treated with physiological levels of glucocorticoid alone, the basal adipogenic response to glucocorticoid is suppressed by PDGF, which is present in bovine serum, and is secreted in an autocrine and/or paracrine fashion by MSCs (Bonner 2010). Addition of imatinib or functional blocking antibodies ameliorates this inhibitory effect allowing differentiation to proceed unabated.

Studies using mouse 3T3-L1 pre-adipocytes and human subcutaneous adipose-derived stem cells have suggested that PDGF-induced activation of PKC $\alpha$ and IKK $\beta$ mediates the inhibitory effect of PDGF on adipogenesis (Artemenko et al. 2005, Gagnon et al. 2009). However, we failed to detect activation of these pathways in response to PDGF in bone marrow-derived MSCs (data not shown), which may be due to cell-type differences or the PDGF isoform used. In hMSCs, PDGF strongly activates the PI3 kinase pathway and previous studies have suggested that the anti-differentiative effects of PDGF could be inhibited using PI3 kinase inhibitors such as Wortmannin and LY94002 (Kratchmarova et al. 2005, Fitter et al. 2008, Martin et al. 2010). Consistent with this view, we have demonstrated that imatinib is a potent inhibitor of PDGF-induced Akt phosphorylation, a major substrate of the PI3 kinase pathway. Furthermore, the pro-adipogenic effect of imatinib, but not that of indomethacin, was negated by 
A

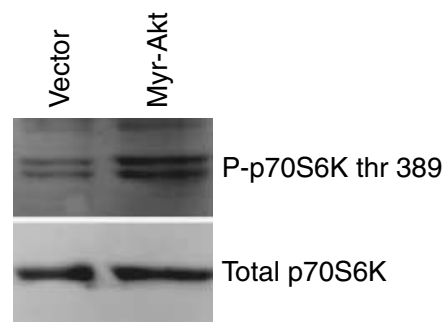

B

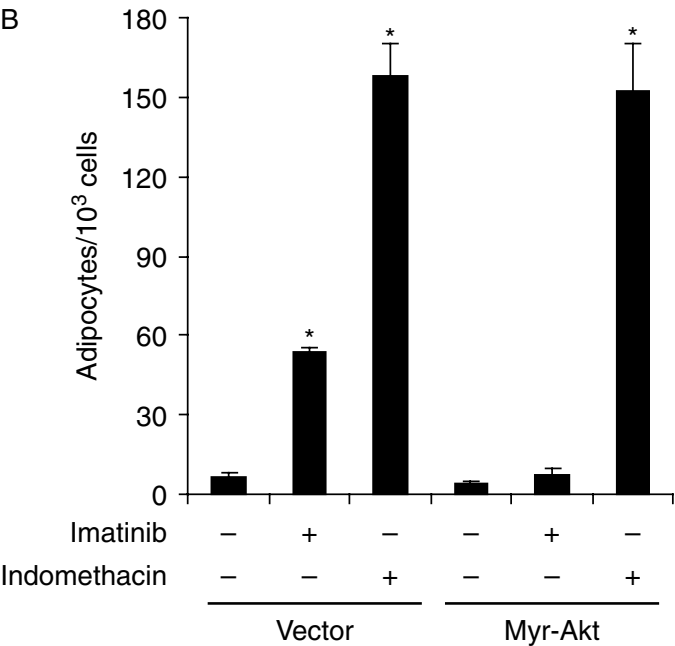

Figure 6 Constitutively activated Akt negates the imatinib response. Myristoylated murine Akt (myr-Akt) and empty vector (vector) were introduced into MSCs by retroviral transduction. (A) Cellular proteins from vector control and myr-Akt-infected cells were harvested, resolved by SDS-PAGE and then transferred to PVDF membranes. The activation status of p70S6K was determined by immunoblotting. (B) Vector control and myrAkt-expressing cells were cultured under induction conditions with vehicle $(0 \cdot 1 \% \mathrm{DMSO})$, imatinib $(3 \mu \mathrm{mol} / \mathrm{l})$ or indomethacin $(60 \mu \mathrm{mol} / \mathrm{l})$ for 28 days. The number of adipocytes was enumerated by counting nile red-labelled cells and DAPI-labelled cell nuclei (mean \pm s.D. of triplicate measurements; ${ }^{*} P<0.001$. One-way ANOVA with Dunnett's post-test).

constitutive activation of Akt. Addition of exogenous EGF to MSC cultures also inhibited imatinib-induced adipogenesis. EGF activates the PI3 kinase pathway in MSCs, albeit to a lesser extent than PDGF (Kratchmarova et al. 2005) and, unlike PDGFR, EGFR is insensitive to imatinib (Buchdunger et al. 2000). The anti-differentiative effects of PI3 kinase signalling on hMSCs was further demonstrated using PIK-75, a selective inhibitor of $\mathrm{p} 110 \alpha$, the catalytic subunit of the obligate heterodimer type I PI3 kinase. PIK-75 promotes hMSC adipogenic differentiation and adiponectin secretion even in the presence of exogenous growth factors. Unlike imatinib, PIK-75 inhibits PI3 kinase activity irrespective of the nature of the mitogen. At the concentrations used in this study, PIK-75, imatinib and anti-PDGFR antibodies inhibit proliferation and suppress the PI3 kinase pathway.
While inhibition of proliferation may be important for the pro-adipogenic effects, studies using $\gamma$-irradiation show that it is not sufficient to promote differentiation under induction conditions (data not shown). Further analysis of Akt substrates that are suppressed or activated in PIK-75- and imatinib-treated MSCs is required to gain further mechanistic insight.

Our hypothesis that inhibition of PI3 kinase, downstream of PDGFR, promotes adipogenic differentiation of bone marrow-derived hMSCs is in contrast to a large body of data demonstrating an essential role for PI3 kinase signalling in adipogenesis in murine cells. Much of this evidence has been obtained using the wellcharacterised murine 3T3-L1 cell line (derived from white adipose tissue), which differentiates into adipocytes in response to insulin. This insulin-mediated differentiation process can be blocked using PI3 kinase inhibitors Wortmannin and LY94002 and by overexpression of a dominant-negative p85 (Sakaue et al. 1998, Xu \& Liao 2004). Furthermore, over-expression of constitutively active forms of PI3 kinase or Akt has been shown to recapitulate the effects of insulin on Glut4 translocation and adipogenic differentiation in these cells (Kohn et al. 1996, Magun et al. 1996). Insulin and the PI3 kinase pathway has also been demonstrated to be essential for adipogenic differentiation in primary mouse cells, as demonstrated by a complete lack of adipocytes and complete abrogation of PI3 kinase activity in murine embryonic fibroblasts (MEFs) isolated from insulin receptor substrate (Irs1 and Irs2) knockout mice (Miki et al. 2001). Furthermore, MEFs isolated from p110 $\alpha$ null mice fail to differentiate into adipocytes in response to insulin (Zhao et al. 2006).

Important distinctions that may account for our findings relate to the intrinsic responsiveness of hMSCs to insulin signalling and to the nature of the proadipogenic stimuli used in our study. Unlike mouse 3T3-L1 cells, hMSCs do not differentiate into adipocytes in response to insulin or insulin-like growth factor 1 (IGF1) alone, instead requiring glucocorticoid to prime the cells to be responsive to pro-adipogenic stimuli (Greenberger 1979, Scavo et al. 2004). In light of this, we have used a differentiation media solely consisting of physiological levels of glucocorticoid to enable us to measure adipogenic responses in the absence of other known pro-adipogenic stimuli including insulin and IGF1. It is therefore possible that PI3 kinase may play a lesser role in transducing differentiation signals in the absence of insulin or IGF1 signalling, as seen in our system. Alternatively, the pro-adipogenic effects of imatinib and PIK-75 may be due to dysregulation of Akt as is seen in MSCs isolated from mice lacking the regulatory subunit of PI3 kinase, p85 $\alpha$. Loss of $\mathrm{p} 85 \alpha$ results in the down-regulation of $\mathrm{p} 110 \alpha$ and hyperactivation of Akt, which induces adipogenesis (Wu et al. 2011). This result suggests that PIK-75 may promote 
adipogenesis by uncoupling the normal regulation of Akt. However, our results indicate that Akt phosphorylation is decreased during PIK-75- or imatinib-mediated differentiation of hMSCs (Supplementary Figure 1, see section on supplementary data given at the end of this article), indicating that Akt signalling is not hyperactivated in response to these drugs under induction conditions. PI3 kinase-independent mechanisms of adipogenic differentiation have also been described. Suppression of MAPK activity in hMSCs has been shown to promote adipogenesis in the absence of insulin and IGF1 signalling (Jaiswal et al. 2000). However, we failed to detect a decrease in the activation status of the MAPK substrates Erk1/2 in the presence of imatinib or PIK-75 during differentiation (Supplementary Figure 1), suggesting that suppression of the MAPK pathway was not responsible for the pro-adipogenic effect of these inhibitors. Conversely, p38 MAPK signalling has been proposed as a pro-adipogenic stimuli, as inhibition of p38 has been shown to negate adipogenic differentiation in hMSCs (Aouadi et al. 2007). However, imatinib suppresses PDGF-induced p38 activation (Fitter et al. 2008), suggesting that activation of p38 MAPK is an unlikely mechanism by which imatinib or PIK-75 promotes adipogenesis.

In cultures treated with PIK-75 or imatinib, the HMW form of adiponectin is the predominant form secreted. Several lines of evidence suggest that the HMW form is the most active with respect to modulating insulin sensitivity (Waki et al. 2003, Lara-Castro et al. 2006, Wang et al. 2006). Consistent with this, analysis of plasma adiponectin complexes in CML patients, before and after 3 months of imatinib therapy, revealed a significant increase in the level of HMW complexes (Fitter et al. 2010). In humans, adiponectin levels correlate negatively with insulin resistance and metabolic syndrome, with low adiponectin levels being associated with a higher risk of type 2 diabetes ( $\mathrm{Li}$ et al. 2009). Thiazolidinedione compounds, a class of anti-diabetic drugs that improve systemic insulin sensitivity, are thought to work, at least in part, by promoting the formation of small adipocytes that secrete high levels of HMW adiponectin (Yamauchi et al. 2001, Phillips et al. 2003, Nawrocki et al. 2006).

In summary, we have identified the PI3 kinase pathway downstream of PDGFR as important in mesenchymal cell differentiation. Inhibition of this pathway, using imatinib or PIK-75, promotes adipogenesis and secretion of HMW adiponectin. In light of this, we hypothesise that inhibition of PDGFR signalling in imatinib-treated CML patients results in increased intramedullary adipogenesis and, subsequently, in an increase in circulating adiponectin levels. These increased adiponectin levels may account for the improvements in glucose and lipid metabolism observed in some imatinib-treated CML patients with concurrent type 2 diabetes.

\section{Supplementary data}

This is linked to the online version of the paper at http://dx.doi.org/ 10.1530/JME-12-0003.

\section{Declaration of interest}

The authors declare that there is no conflict of interest that could be perceived as prejudicing the impartiality of the research reported.

\section{Funding}

This work was funded by a Translational Research Grant from the Leukaemia and Lymphoma Society (grant number 6040-09) awarded to A C W Z.

\section{Acknowledgements}

Imatinib mesylate was kindly provided by Novartis Pharmaceuticals.

\section{References}

Aouadi M, Jager J, Laurent K, Gonzalez T, Cormont M, Binetruy B, Le Marchand-Brustel Y, Tanti JF \& Bost F 2007 p38MAP kinase activity is required for human primary adipocyte differentiation. FEBS Letters 581 5591-5596. (doi:10.1016/j.febslet.2007.10.064)

Artemenko Y, Gagnon A, Aubin D \& Sorisky A 2005 Anti-adipogenic effect of PDGF is reversed by PKC inhibition. Journal of Cellular Physiology 204 646-653. (doi:10.1002/jcp.20314)

Bonner JC 2010 Mesenchymal cell survival in airway and interstitial pulmonary fibrosis. Fibrogenesis \& Tissue Repair 3 15. (doi:10.1186/ 1755-1536-3-15)

Breccia M, Muscaritoli M, Aversa Z, Mandelli F \& Alimena G 2004 Imatinib mesylate may improve fasting blood glucose in diabetic $\mathrm{Ph}+$ chronic myelogenous leukemia patients responsive to treatment. Journal of Clinical Oncology 22 4653-4655. (doi:10.1200/ JCO.2004.04.217)

Breccia M, Muscaritoli M \& Alimena G 2005 Reduction of glycosylated hemoglobin with stable insulin levels in a diabetic patient with chronic myeloid leukemia responsive to imatinib. Haematologica 90 (Suppl) ECR21.

Buchdunger E, Cioffi CL, Law N, Stover D, Ohno-Jones S, Druker BJ \& Lydon NB $2000 \mathrm{Abl}$ protein-tyrosine kinase inhibitor STI571 inhibits in vitro signal transduction mediated by c-kit and plateletderived growth factor receptors. Journal of Pharmacology and Experimental Therapeutics 295 139-145.

Chaudhary LR, Hofmeister AM \& Hruska KA 2004 Differential growth factor control of bone formation through osteoprogenitor differentiation. Bone 34 402-411. (doi:10.1016/j.bone.2003.11.014)

Chaussade C, Rewcastle GW, Kendall JD, Denny WA, Cho K, Gronning LM, Chong ML, Anagnostou SH, Jackson SP, Daniele N et al. 2007 Evidence for functional redundancy of class IA PI3K isoforms in insulin signalling. Biochemical Journal 404 449-458. (doi:10.1042/ BJ20070003)

le Coutre P, Kreuzer KA, Pursche S, Bonin M, Leopold T, Baskaynak G, Dorken B, Ehninger G, Ottmann O, Jenke A et al. 2004 
Pharmacokinetics and cellular uptake of imatinib and its main metabolite CGP74588. Cancer Chemotherapy and Pharmacology 53 313-323. (doi:10.1007/s00280-003-0741-6)

Dewar AL, Cambareri AC, Zannettino AC, Miller BL, Doherty KV, Hughes TP \& Lyons AB 2005 Macrophage colony-stimulating factor receptor c-fms is a novel target of imatinib. Blood 105 3127-3132. (doi:10.1182/blood-2004-10-3967)

Dewar AL, Farrugia AN, Condina MR, Bik To L, Hughes TP, Vernon-Roberts B \& Zannettino AC 2006 Imatinib as a potential antiresorptive therapy for bone disease. Blood 107 4334-4337. (doi:10.1182/blood-2005-09-3568)

Druker BJ 2004 Imatinib as a paradigm of targeted therapies. Advances in Cancer Research 91 1-30. (doi:10.1016/S0065-230X(04)91001-9)

Fierro F, Illmer T, Jing D, Schleyer E, Ehninger G, Boxberger S \& Bornhauser M 2007 Inhibition of platelet-derived growth factor receptor $\beta$ by imatinib mesylate suppresses proliferation and alters differentiation of human mesenchymal stem cells in vitro. Cell Proliferation 40 355-366. (doi:10.1111/j.1365-2184.2007.00438.x)

Fitter S, Dewar AL, Kostakis P, To LB, Hughes TP, Roberts MM, Lynch K, Vernon-Roberts B \& Zannettino AC 2008 Long-term imatinib therapy promotes bone formation in CML patients. Blood 111 2538-2547. (doi:10.1182/blood-2007-07-104281)

Fitter S, Vandyke K, Schultz CG, White D, Hughes TP \& Zannettino AC 2010 Plasma adiponectin levels are markedly elevated in imatinibtreated chronic myeloid leukemia (CML) patients: a mechanism for improved insulin sensitivity in type 2 diabetic CML patients? Journal of Clinical Endocrinology and Metabolism 95 3763-3767. (doi:10.1210/jc.2010-0086)

Gagnon A, Landry A \& Sorisky A 2009 IKK $\beta$ and the anti-adipogenic effect of platelet-derived growth factor in human abdominal subcutaneous preadipocytes. Journal of Endocrinology 201 75-80. (doi:10.1677/JOE-08-0411)

Gimble J 1998 Marrow stromal adipocytes. In Marrow Stromal Cell Culture, pp 67-87. Eds JN Beresford \& ME Owen. Cambridge: Cambridge University Press.

Gologan R, Constantinescu G, Georgescu D, Ostroveanu D, Vasilache D, Dobrea C, Iancu D \& Popov V 2009 Hypolipemiant besides antileukemic effect of imatinib mesylate. Leukemia Research 33 1285-1287. (doi:10.1016/j.leukres.2009.02.024)

Greenberger JS 1979 Corticosteroid-dependent differentiation of human marrow preadipocytes in vitro. In Vitro 15 823-828. (doi:10.1007/BF02618309)

Hagerkvist R, Sandler S, Mokhtari D \& Welsh N 2007 Amelioration of diabetes by imatinib mesylate (Gleevec): role of $\beta$-cell NF-kappaB activation and anti-apoptotic preconditioning. FASEB Journal 21 618-628. (doi:10.1096/fj.06-6910com)

Han MS, Chung KW, Cheon HG, Rhee SD, Yoon CH, Lee MK, Kim KW \& Lee MS 2009 Imatinib mesylate reduces endoplasmic reticulum stress and induces remission of diabetes in $\mathrm{db} / \mathrm{db}$ mice. Diabetes $\mathbf{5 8}$ 329-336. (doi:10.2337/db08-0080)

Hay N \& Sonenberg N 2004 Upstream and downstream of mTOR. Genes and Development 18 1926-1945. (doi:10.1101/gad.1212704)

Hock JM \& Canalis E 1994 Platelet-derived growth factor enhances bone cell replication, but not differentiated function of osteoblasts. Endocrinology 134 1423-1428. (doi:10.1210/en.134.3.1423)

Isenmann S, Arthur A, Zannettino AC, Turner JL, Shi S, Glackin CA \& Gronthos S 2009 TWIST family of basic helix-loop-helix transcription factors mediate human mesenchymal stem cell growth and commitment. Stem Cells 27 2457-2468. (doi:10.1002/stem.181)

Jaiswal RK, Jaiswal N, Bruder SP, Mbalaviele G, Marshak DR \& Pittenger MF 2000 Adult human mesenchymal stem cell differentiation to the osteogenic or adipogenic lineage is regulated by mitogen-activated protein kinase. Journal of Biological Chemistry $\mathbf{2 7 5}$ 9645-9652. (doi:10.1074/jbc.275.13.9645)

Jonsson S, Olsson B, Ohlsson C, Lorentzon M, Mellstrom D \& Wadenvik H 2008 Increased cortical bone mineralization in imatinib treated patients with chronic myelogenous leukemia. Haematologica 93 1101-1103. (doi:10.3324/haematol.12373)
Jonsson S, Hjorth-Hansen H, Olsson B, Wadenvik H, Sundan A \& Standal T 2012 Imatinib inhibits proliferation of human mesenchymal stem cells and promotes early but not late osteoblast differentiation in vitro. Journal of Bone and Mineral Metabolism 30 119-123. (doi:10.1007/s00774-011-0323-3)

Justesen J, Mosekilde L, Holmes M, Stenderup K, Gasser J, Mullins JJ, Seckl JR \& Kassem M 2004 Mice deficient in 11ß-hydroxysteroid dehydrogenase type 1 lack bone marrow adipocytes, but maintain normal bone formation. Endocrinology 145 1916-1925. (doi:10.1210/en.2003-1427)

Kohn AD, Summers SA, Birnbaum MJ \& Roth RA 1996 Expression of a constitutively active Akt Ser/Thr kinase in 3T3-L1 adipocytes stimulates glucose uptake and glucose transporter 4 translocation. Journal of Biological Chemistry 271 31372-31378. (doi:10.1074/jbc. 271.49.31372)

Kratchmarova I, Blagoev B, Haack-Sorensen M, Kassem M \& Mann M 2005 Mechanism of divergent growth factor effects in mesenchymal stem cell differentiation. Science 308 1472-1477. (doi:10.1126/ science.1107627)

Kubota K, Sakikawa C, Katsumata M, Nakamura T \& Wakabayashi K 2002 Platelet-derived growth factor BB secreted from osteoclasts acts as an osteoblastogenesis inhibitory factor. Journal of Bone and Mineral Research 17 257-265. (doi:10.1359/jbmr.2002.17.2.257)

Lara-Castro C, Luo N, Wallace P, Klein RL \& Garvey WT 2006 Adiponectin multimeric complexes and the metabolic syndrome trait cluster. Diabetes 55 249-259. (doi:10.2337/diabetes.55.01.06.db05-1105)

Lehmann JM, Lenhard JM, Oliver BB, Ringold GM \& Kliewer SA 1997 Peroxisome proliferator-activated receptors $\alpha$ and gamma are activated by indomethacin and other non-steroidal antiinflammatory drugs. Journal of Biological Chemistry 272 3406-3410. (doi:10.1074/jbc.272.6.3406)

Li S, Shin HJ, Ding EL \& van Dam RM 2009 Adiponectin levels and risk of type 2 diabetes: a systematic review and meta-analysis. Journal of the American Medical Association 302 179-188. (doi:10.1001/jama. 2009.976)

Louvet C, Szot GL, Lang J, Lee MR, Martinier N, Bollag G, Zhu S, Weiss A \& Bluestone JA 2008 Tyrosine kinase inhibitors reverse type 1 diabetes in nonobese diabetic mice. PNAS 105 18895-18900. (doi:10.1073/pnas.0810246105)

Magun R, Burgering BM, Coffer PJ, Pardasani D, Lin Y, Chabot J \& Sorisky A 1996 Expression of a constitutively activated form of protein kinase B (c-Akt) in 3T3-L1 preadipose cells causes spontaneous differentiation. Endocrinology 137 3590-3593. (doi:10.1210/en.137.8.3590)

Mariani S, Tornaghi L, Sassone M, Basciani S, Buzzetti R, Gambacorti-Passerini C, Spera G \& Gnessi L 2010 Imatinib does not substantially modify the glycemic profile in patients with chronic myeloid leukaemia. Leukemia Research 34 e5-e7. (doi:10.1016/j. leukres.2009.08.003)

Martin SK, Fitter S, Bong LF, Drew JJ, Gronthos S, Shepherd PR \& Zannettino AC 2010 NVP-BEZ235, a dual pan class I PI3 kinase and mTOR inhibitor, promotes osteogenic differentiation in human mesenchymal stromal cells. Journal of Bone and Mineral Research $\mathbf{2 5}$ 2126-2137. (doi:10.1002/jbmr.114)

Miki H, Yamauchi T, Suzuki R, Komeda K, Tsuchida A, Kubota N, Terauchi Y, Kamon J, Kaburagi Y, Matsui J et al. 2001 Essential role of insulin receptor substrate 1 (IRS-1) and IRS-2 in adipocyte differentiation. Molecular and Cellular Biology 21 2521-2532. (doi:10.1128/MCB.21.7.2521-2532.2001)

Nawrocki AR, Rajala MW, Tomas E, Pajvani UB, Saha AK, Trumbauer ME, Pang Z, Chen AS, Ruderman NB, Chen H et al. 2006 Mice lacking adiponectin show decreased hepatic insulin sensitivity and reduced responsiveness to peroxisome proliferator-activated receptor gamma agonists. Journal of Biological Chemistry 281 2654-2660. (doi:10.1074/ jbc.M505311200)

O'Sullivan S, Horne A, Wattie D, Porteous F, Callon K, Gamble G, Ebeling P, Browett P \& Grey A 2009 Decreased bone turnover 
despite persistent secondary hyperparathyroidism during prolonged treatment with imatinib. Journal of Clinical Endocrinology and Metabolism 94 1131-1136. (doi:10.1210/jc.2008-2324)

Phillips SA, Ciaraldi TP, Kong AP, Bandukwala R, Aroda V, Carter L, Baxi S, Mudaliar SR \& Henry RR 2003 Modulation of circulating and adipose tissue adiponectin levels by antidiabetic therapy. Diabetes 52 667-674. (doi:10.2337/diabetes.52.3.667)

Pittenger MF, Mackay AM, Beck SC, Jaiswal RK, Douglas R, Mosca JD, Moorman MA, Simonetti DW, Craig S \& Marshak DR 1999 Multilineage potential of adult human mesenchymal stem cells. Science 284 143-147. (doi:10.1126/science.284.5411.143)

Sakaue H, Ogawa W, Matsumoto M, Kuroda S, Takata M, Sugimoto T, Spiegelman BM \& Kasuga M 1998 Posttranscriptional control of adipocyte differentiation through activation of phosphoinositide 3-kinase. Journal of Biological Chemistry 273 28945-28952. (doi:10.1074/ jbc.273.44.28945)

Scavo LM, Karas M, Murray M \& Leroith D 2004 Insulin-like growth factor-I stimulates both cell growth and lipogenesis during differentiation of human mesenchymal stem cells into adipocytes. Journal of Clinical Endocrinology and Metabolism 89 3543-3553. (doi:10.1210/jc.2003-031682)

Serra V, Markman B, Scaltriti M, Eichhorn PJ, Valero V, Guzman M, Botero ML, Llonch E, Atzori F, Di Cosimo S et al. 2008 NVP-BEZ235, a dual PI3K/mTOR inhibitor, prevents PI3K signaling and inhibits the growth of cancer cells with activating PI3K mutations. Cancer Research 68 8022-8030. (doi:10.1158/0008-5472.CAN-08-1385)

Tokunaga A, Oya T, Ishii Y, Motomura H, Nakamura C, Ishizawa S, Fujimori T, Nabeshima Y, Umezawa A, Kanamori M et al. 2008 PDGF receptor $\beta$ is a potent regulator of mesenchymal stromal cell function. Journal of Bone and Mineral Research 23 1519-1528. (doi:10.1359/jbmr.080409)

Tsapas A, Vlachaki E, Sarigianni M, Klonizakis F \& Paletas K 2008 Restoration of insulin sensitivity following treatment with imatinib mesylate (Gleevec) in non-diabetic patients with chronic myelogenic leukemia (CML). Leukemia Research 32 674-675. (doi:10.1016/j.leukres.2007.08.014)

Vandyke K, Dewar AL, Diamond P, Fitter S, Schultz CG, Sims NA \& Zannettino AC $2010 a$ The tyrosine kinase inhibitor dasatinib dysregulates bone remodeling through inhibition of osteoclasts in vivo. Journal of Bone and Mineral Research 25 1759-1770. (doi:10.1002/jbmr.85)
Vandyke K, Fitter S, Dewar AL, Hughes TP \& Zannettino AC $2010 b$ Dysregulation of bone remodeling by imatinib mesylate. Blood 115 766-774. (doi:10.1182/blood-2009-08-237404)

Veneri D, Franchini M \& Bonora E 2005 Imatinib and regression of type 2 diabetes. New England Journal of Medicine 352 1049-1050. (doi:10.1056/NEJM200503103521023)

Waki H, Yamauchi T, Kamon J, Ito Y, Uchida S, Kita S, Hara K, Hada Y, Vasseur F, Froguel P et al. 2003 Impaired multimerization of human adiponectin mutants associated with diabetes. Molecular structure and multimer formation of adiponectin. Journal of Biological Chemistry 278 40352-40363. (doi:10.1074/jbc. M300365200)

Wang Y, Lam KS, Chan L, Chan KW, Lam JB, Lam MC, Hoo RC, Mak WW, Cooper GJ \& Xu A 2006 Post-translational modifications of the four conserved lysine residues within the collagenous domain of adiponectin are required for the formation of its high molecular weight oligomeric complex. Journal of Biological Chemistry 281 16391-16400. (doi:10.1074/jbc.M513907200)

Wu X, Chen S, Orlando SA, Yuan J, Kim ET, Munugalavadla V, Mali RS, Kapur R \& Yang FC 2011 p85 $\alpha$ regulates osteoblast differentiation by cross-talking with the MAPK pathway. Journal of Biological Chemistry 286 13512-13521. (doi:10.1074/jbc.M110.187351)

Xu J \& Liao K 2004 Protein kinase B/AKT 1 plays a pivotal role in insulin-like growth factor-1 receptor signaling induced 3T3-L1 adipocyte differentiation. Journal of Biological Chemistry $\mathbf{2 7 9}$ 35914-35922. (doi:10.1074/jbc.M402297200)

Yamauchi T, Kamon J, Waki H, Murakami K, Motojima K, Komeda K, Ide T, Kubota N, Terauchi Y, Tobe K et al. 2001 The mechanisms by which both heterozygous peroxisome proliferator-activated receptor gamma (PPARgamma) deficiency and PPARgamma agonist improve insulin resistance. Journal of Biological Chemistry 276 41245-41254. (doi:10.1074/jbc.M103241200)

Zhao JJ, Cheng H, Jia S, Wang L, Gjoerup OV, Mikami A \& Roberts TM 2006 The $\mathrm{p} 110 \alpha$ isoform of PI3K is essential for proper growth factor signaling and oncogenic transformation. PNAS 103 16296-16300. (doi:10.1073/pnas.0607899103)

Received in final form 27 March 2012

Accepted 2 April 2012

Made available online as an Accepted Preprint 2 April 2012 